\title{
PENGEMBANGAN STRATEGI BISNIS RESTORAN SEGMEN ATAS DI YOGYAKARTA DENGAN PENDEKATAN CRITICAL SUCCESS FACTORS
}

\section{HIGH CLASS SEGMENT RESTAURANT BUSINESS STRATEGY DEVELOPMENT IN YOGYAKARTA WITH CRITICAL SUCCESS FACTORS APROACH}

\author{
Edouard Aryadi Supriyadi $^{1)}$, Wahyu Supartono ${ }^{2)}$, dan Didik Purwadi2 ${ }^{2}$ ** \\ ${ }^{1)}$ Sekolah Tinggi Pariwisata Ambarukmo (Stipram) Yogyakarta \\ ${ }^{2}$ Departemen Teknologi Industri Pertanian, Fakultas Teknologi Pertanian, Universitas Gadjah Mada, \\ Jl. Flora No. 1, Bulaksumur, Yogyakarta 55281 \\ *Email: didik@ugm.ac.id
}

Makalah: Diterima 23 September 2020; Diperbaiki 07 Desember 2020; Disetujui 17 Desember 2020

\begin{abstract}
Yogyakarta is the right place to run a culinary business because of Yogyakarta's status as a city of culture, education city, and tourist destination, so it requires restaurant facilities, including for the high class segment. The right business strategy is needed to minimize the risk of competing and maximize the advantages of competition. The object of this research was GW restaurants and the comparisons were $L D$ and SS restaurants. This research was aimed at identifying success factors, analyzing the business environment, and developing its business strategy. This research used descriptive-qualitative techniques with Critical Success Factors (CSF) and SWOT approaches. GW restaurants had Critical Success Factors, namely clear concepts, strong customer relationships, cultural interests, managing a competitive environment, good customer relationships, and determining the right location/place. The business environment consisted of internal and external. The development of its business strategy is to improve the quality of employees, improve the quality of its products and innovations, favor specific menus, increase service time, and conduct advertising promotions and expand the network with social media.
\end{abstract}

Keywords: business strategy, critical success factors, restaurant

\section{ABSTRAK}

Yogyakarta adalah tempat yang tepat untuk menjalankan bisnis kuliner karena status Yogyakarta sebagai kota budaya, kota pendidikan, dan kota tujuan wisata, sehingga membutuhkan fasilitas restoran, termasuk untuk segmen atas. Strategi bisnis yang tepat sangat dibutuhkan untuk meminimalkan resiko bersaing dan memaksimalkan keunggulan kompetisi. Objek penelitian ini adalah restoran GW dengan pembanding adalah restoran LD dan SS. Penelitian ini bertujuan mengidentifkasi faktor-faktor kesuksesan, menganalisis lingkungan bisnis, dan mengembangkan strategi bisnisnya. Penelitian ini menggunakan teknik deskriptif-kualitatif dengan pendekatan Critical Success Factors (CSF) dan SWOT. Restoran GW memiliki Critical Success Factors, yakni konsep jelas, hubungan dengan pelanggan kuat, adanya ketertarikan budaya, mengelola lingkungan yang kompetitif, hubungan dengan konsumen yang baik, dan penentuan lokasi/tempat yang tepat. Lingkungan bisnis terdiri atas internal dan eksternal. Pengembangan strategi bisnisnya adalah meningkatkan mutu karyawan, meningkatkan mutu produk dan inovasinya, mengunggulkan menu spesifik, menambah waktu pelayanan, serta melakukan promosi iklan dan memperluas jaringan dengan media sosial.

Kata kunci: Critical Success Factros, strategi bisnis, restoran

\section{PENDAHULUAN}

Yogyakarta dikenal sebagai kota kebudayaan, kota pendidikan dan kota pariwisata. Hal ini menyebabkan banyak orang berdatangan ke Yogyakarta. Peluang bisnispun muncul antara lain tumbuh dan berkembang industri kuliner. Industri kuliner ini berkembang sejalan dengan berkembangnya tempat makan, termasuk restoran, yang tersedia dari segmen bawah seperti kaki lima dan angkringan, hingga untuk segmen atas seperti café dan restoran. Menurut Indrayana (2006), restoran segmen atas yaitu restoran untuk penikmat cita rasa, berpenampilan resmi, makanan disajikan dengan mewah bernuansa restoran yang elegan dan mewah. Restoran segmen bawah menyajikan makanan dan minuman dengan harga murah, kemudian tidak harus menggunakan pakaian mewah, dan menu yang disediakan terbatas. Perkembangan jumlah restoran dan rumah makan sebagaimana pada Tabel 1. Selama kurun waktu 4 tahun jumlah restoran DIY naik 76\% dari 600 buah di tahun 2016 menjadi 1.056 buah di tahun 2020. Sementara itu jumlah rumah makan relatif sama, yakni 1.162 buah tahun 2016 turun sedkit menjadi 1.037 buah pada tahun 2020 (Anonim, 2020). 
Tabel 1. Restoran dan rumah makan di Yogyakarta

\begin{tabular}{lccccc}
\hline Jenis & $\mathbf{2 0 1 6}$ & $\mathbf{2 0 1 7}$ & $\mathbf{2 0 1 8}$ & $\mathbf{2 0 1 9}$ & $\mathbf{2 0 2 0}$ \\
\hline Restoran & 600,00 & 437,00 & $1.163,00$ & $1.002,00$ & $1.056,00 *$ \\
Rumah makan & $1.162,00$ & $1.284,00$ & 846,00 & $1.007,00$ & $1.037,00$ \\
\hline Sumber : Anonim $(2020)$ & & & &
\end{tabular}

Sumber : Anonim (2020)

Tabel 1 menunjukkan bahwa jumlah restoran dan rumah makan semakin banyak. Hal ini tentu akan meningkatkan tingkat persaingan semakin ketat dalam berbisnis kuliner ini. Pelaku bisnis harus memiliki strategi bisnis yang tepat. Kemampuan dalam menyusun strategi ini cukup penting karena kemampuan menyusun strategi merupakan bagian dari kegiatan yang dirancang untuk menjalankan aktivitas berbisnis. Semakin baik dan tepat strategi bisnis yang diterapkan oleh sebuah restoran, semakin kuat dalam menghadapi persaingan bisnis dan mampu unggul dalam persaingan (Sarjono, 2013).

Strategi bisnis disusun dengan memperhatikan berbagai faktor penentu, atau faktor sukses. Disamping itu, restoran juga perlu memperhatikan siklus bisnis dengan memperhatikan berbagai faktor penting pendukungnya (Skare, 2015). Dinamika konsumen atau pelanggan, khususnya pelanggan wisatawan tentu memiliki sifat yang khas. Hal ini sejalan dengan pendapat Smart (2009) yang menegaskan bahwa pemahaman manajemen proses bisnis menjadi sebuah keharusan agar bisnis yang dijalani dapat selalu bersaing. Menurut Thompson et al. (2016), strategi sebuah perusahaan adalah aksi untuk mengalahkan para pesaingnya dan mencapai profitabilitas superior. Lebih lanjut, Purwadi (2018) menjelaskan bahwa penelitian menggunakan pendekatan deskriptif kualitatif, dengan teknik SWOT dan strategi disagregasi, dapat menghasilkan rumusan strategi operasional. Demikian pula Gurhananda dan Wandebori (2014) telah menyusun strategi pengembangan restoran dengan pendekatan SWOT

Putri et al. (2014) dan Setyorini et al. (2016) menjelaskan bahwa metode SWOT telah dignakan untuk kasus restoran makanan cepat saji, agar memiliki alternatif perencanaan strategi dan prioritas strategi pengembangannya. Lebih lanjut Rahman dan Rahmah (2018) menegaskan bahwa identifikasi alternatif strategi bisnis Kadatuan Koffie dilakukan menggunakan analisis SWOT. Hasil analisis SWOT kuantitatif menunjukkan bahwa Kadatuan Koffie memiliki kondisi internal yang kuat namun masih sedikit kelemahan pada kondisi eksternalnya, dengan pilihan alternatif strategi ST yaitu (1) mengutamakan kualitas produk sebagai daya saing dan (2) menjaga tingkat harga jual produk.

Tujuan penelitian ini adalah untuk mengidentifkasi faktor-faktor kesuksesan, menganalisis lingkungan bisnis, dan mengembangkan strategi bisnisnya.

\section{METODE PENELITIAN}

Objek penelitian adalah 3 buah restoran segmen atas di Yogyakarta, yaitu GW, SS dan OD. Narasumber adalah 3 orang manajemen restoran, 15 orang karyawan restoran dan 30 orang pelanggan restoran. Pemilihan narasumber menggunakan purposive sampling, dengan pertimbangan keberagaman. Waktu pelaksanaan adalah bulan JuniDesember 2018. Jenis data yang digunakan merupakan data primer yang diperoleh melalui metode wawancara mendalam (in depth interview) dengan narasumber stakeholder Restoran GW dan sebagai pembanding adalah Restoran SS dan OD. Teknik analisis menggunakan pendekatan deskriptifkualitatif, yakni mengidentifikasi faktor kesuksesan Restoran GW melalui analisis Critical Success Factor (CSF). Rumusan strategi bisnis disusun berdasarkan Teknik SWOT, yakni Teknik penyusunan strategi yang didasarkan atas identifikasi kekuatan, kelemahan, peluang dan ancaman; yang disusun berdasarkan dari faktor kesuksesan bisnis restoran. Konsep CSF meliputi faktor konsep, faktor hubungan dengan pegawai, budaya, lingkungan yang kompetitif, hubungan dengan konsumen, dan pemilihan lokasi/ tempat.

\section{HASIL DAN PEMBAHASAN}

\section{Analisis Faktor Kesuksesan Kritis (CSF)}

Tabel 2 menggambarkan bagaimana faktor kesuksesan kritis (Critial Success Factors) berperan dalam kemampuan bersaing. Ada 6 faktor kesuksesan digunakan, yaitu :
a. Kosep
b. Hubungan dengan karyawan
c. Ketertarikan budaya
d. Lingkungan persaingan
e. Hubungan dengan pelanggan
f. Pemilihan lokasi/ tempat

Restoran GW merupakan restoran segmen atas yang dapat bertahan meski berbagai tantangan muncul saat ini. Sejak berdiri tahun 1996 hingga kini selalu fokus pada kekuatan internalnya, sebagai fakor kesuksesan. Faktor penentu keberhasilannya berdasarkan konsep CSF ini sangat sesuai dengan Muslim et al. (2011), bahwa faktor keberhasilan dalam sebuah bisnis yaitu keyakinan kepada Tuhan yang Maha Esa sebagai faktor utamanya. Beberapa faktor lainnya yaitu, kejujuran, pelayanan terhadap pelanggan, harga yang terjangkau, kualitas dan kuantitas pelayanan yang baik, kesungguhan dalam berbisnis, mengenali faktor lingkungan, 
keberuntungan, peluang dan pekerja yang di training agar terampil.

Menurut Ward et al. (2002) Critical Success Factor (CSF) merupakan beberapa area kunci dimana sesuatu harus berjalan dengan baik sehingga keberhasilan bisnis dapat dicapai. Critical success factor (CSF) dapat ditentukan jika objektif organisasi telah diindentifikasi. Tujuan dari CSF adalah mengintrepetasikan objektif secara lebih jelas untuk menetukan aktivitas yang harus dilakukan dan informasi apa yang dibutuhkan. Penelitian ini dilakukan dengan menggunakan CSF sebagai metode dalam menganalisis faktor keberhasilan apa yang ada pada restoran GW.

Ada beberapa konsep yang dapat mendukung eksistensi sebuah restoran, pada khususnya restoran segmen atas. Konsep-konsep tersebut tercipta agar sebuah restoran tidak kehilangan identitasnya. Identitas berfungi untuk memperkuat alasan mengapa restoran tersebut tetap bertahan lama. Gikonyo (2015) menjelaskan bahwa untuk kesuksesan sebuah restoran dalam pasar bisnis, restoran harus menjaga konsep yang kuat pada restoran tersebut. Konsep dasar yang dimiliki restoran GW seperti mengutamakan kualitas makanan, berpikir jangka panjang, dan menjadi restoran yang berbeda dari yang lain yaitu, pentingnya seorang pemilik restoran mengerti dapur atau dapat memasak. Hal ini diperlukan karena kualitas makanan dapat dijaga sendiri oleh pemilik restoran. Hal ini sejalan pula pendapat Skare (2015) dan Smart (2009).

Hubungan dengan karyawan sebagai salah satu kunci bertahannya restoran GW. Hal tersebut dikatakan oleh Devito (2009) bahwa, komunikasi adalah tingkat kedalaman dan keluasan pesan yang terjadi saat berkomunikasi dengan orang. Intensitas komunikasi yang terjadi secara mendalam ditandai dengan adanya kejujuran, keterbukaan, dan saling percaya yang dapat memunculkan suatu respon dalam bentuk perilaku atau tindakan. Manajemen dinilai oleh karyawan sangat baik dan Pimpinan sangat menjaga keharmonisan dengan karyawan.

Tabel 2. Hasil CSF Restoran GW

\begin{tabular}{|c|c|c|c|}
\hline No & Faktor CSF & Kondisi ideal & Temuan \\
\hline 1 & Konsep & $\begin{array}{l}\text { Mencari peluang } \\
\text { dengan membuat } \\
\text { sesuatu yang } \\
\text { berbeda dari } \\
\text { restoran lain yang } \\
\text { sudah ada }\end{array}$ & $\begin{array}{l}\text { - } \quad \text { konsep bisnis, meliputi konsep menu utama restoran, yakni } \\
\text { Konsep 3I (Indonesia, Italia, India). } \\
\text { - } \quad \text { konsep pelayanan sebagai konsep dasar yang kuat/ fondasi } \\
\text { restoran seperti quality, the long term, make something different. } \\
\text { - } \quad \text { konsep presentasi high end, agar makanan Indonesia bisa sejajar } \\
\text { dengan makanan westren. } \\
\text { - } \quad \text { konsep bangunan fisik heritage peninggalan Belanda. }\end{array}$ \\
\hline 2 & $\begin{array}{l}\text { Hubungan } \\
\text { dengan } \\
\text { karyawan }\end{array}$ & $\begin{array}{l}\text { Pentingnya } \\
\text { menjaga hubungan } \\
\text { dengan karyawan/ } \\
\text { pegawai di } \\
\text { restoran }\end{array}$ & $\begin{array}{l}\text { - Mampu memimpin dirinya sendiri } \\
\text { - Membuat rasa nyaman di dalam diri karyawan/ pegawai dengan } \\
\text { cara komunikasi yang baik } \\
\text { Menempatkan diri, kapan harus keras, kapan harus bisa jadi temen, } \\
\text { kapan bisa jadi bawahan, kapan menjadi atasan. } \\
\text { - Melakukan keramah-tamahan dalam pelayanan, karena ini } \\
\text { merupakan ujung tombak bisnis }\end{array}$ \\
\hline 3 & $\begin{array}{l}\text { Ketertarikan } \\
\text { budaya }\end{array}$ & $\begin{array}{l}\text { Budaya diterapkan } \\
\text { sebagai konsep } \\
\text { daya tarik restoran }\end{array}$ & $\begin{array}{l}\text { - Arsitektur budaya pada bangunan restoran dapat menarik minat } \\
\text { konsumen } \\
\text { - } \quad \text { Restoran dengan nuansa budaya peninggalan sejarah } \\
\text { - Presentasi makanan nusantara yang memilliki ciri khas budaya } \\
\text { daerah }\end{array}$ \\
\hline 4 & $\begin{array}{l}\text { Lingkungan } \\
\text { persaingan }\end{array}$ & $\begin{array}{l}\text { Kemampuan } \\
\text { mengelola } \\
\text { persaingan }\end{array}$ & $\begin{array}{l}\text { - Manajemen selalu mengontrol, dan jangan hanya mengadalkan } \\
\text { karyawan/pegawai. } \\
\text { - Menjaga kualitas makanan, presentasi makanan, } \\
\text { - Pelanggan adalah raja, maka pilihan makanan bisa sesuai } \\
\text { keinginan konsumen } \\
\text { - Kompetitor dijadikan sebagai tantangan } \\
\text { - Menjaga keberlangsungan bisnis dengan melakukan pelayanan } \\
\text { lebih baik dari pada pesaing. }\end{array}$ \\
\hline 5 & $\begin{array}{l}\text { Hubungan } \\
\text { dengan } \\
\text { pelanggan }\end{array}$ & $\begin{array}{l}\text { Menjaga loyalitas } \\
\text { konsumen kepada } \\
\text { restoran }\end{array}$ & $\begin{array}{l}\text { - Memberikan pelayanan yang terbaik tanpa mengeluh } \\
\text { - Memberikan rasa nyaman seperti berada "dirumah" ketika berada } \\
\text { - Service excelent merupakan suatu hal penting untuk membuat } \\
\text { konsumen kembali lagi }\end{array}$ \\
\hline 6 & $\begin{array}{l}\text { Pemilihan } \\
\text { lokasi/ tempat }\end{array}$ & $\begin{array}{l}\text { Pentingnya dalam } \\
\text { pemilihan tempat } \\
\text { atau lokasi }\end{array}$ & $\begin{array}{l}\text { - Suasana rilek dirancang dengan membangun hutan kecil didekat } \\
\text { sungai } \\
\text { - } \quad \text { Berdekatan dengan calon pelanggan }\end{array}$ \\
\hline
\end{tabular}


Pentingnya menjaga konsep budaya dalam lingkungan restoran dapat membuat konsumen ingin datang lagi. Peran faktor budaya ini sesuai dengan pendapat Kotler (2005), bahwa beberapa faktor yang dapat mempengaruhi perilaku pembelian diantaranya adalah faktor budaya, sosial, pribadi, dan psikologis. Lingkungan persaingan merupakan salah satu faktor yang mempengaruhi faktor kesuksesan sebuah usaha restoran. Jumlah pengunjung restoran pertahun untuk GW sebesar 22.168 orang, SS sebanyak 17.911 orang, dan OD sebanyak 26.563 orang. Tabel 3 berikut menjelaskan perkembangan jumlah pelanggan di ketiga restoran tersebut

Tabel 3. Data Pengunjung restoran (orang) 2018

\begin{tabular}{|c|c|c|c|c|}
\hline \multirow{2}{*}{ No } & \multirow{2}{*}{ Bulan } & \multicolumn{3}{|c|}{ Restoran } \\
\hline & & GW & SS & OD \\
\hline 1. & Januari & 1.386 & 1.038 & 1.688 \\
\hline 2. & Februari & 1.391 & 1.043 & 1.770 \\
\hline 3. & Maret & 1.375 & 1.027 & 1.562 \\
\hline 4. & April & 1.476 & 1.165 & 1.824 \\
\hline 5. & Mei & 2.052 & 1.710 & 1.877 \\
\hline 6. & Juni & 2.071 & 1.675 & 2.241 \\
\hline 7. & Juli & 2.043 & 1.767 & 1.817 \\
\hline 8. & Agustus & 2.059 & 1.653 & 3.190 \\
\hline 9. & September & 2.075 & 1.715 & 2.667 \\
\hline 10. & Oktober & 2.100 & 1.690 & 2.853 \\
\hline 11. & November & 2.083 & 1.683 & 2.401 \\
\hline 12. & Desember & 2.057 & 1.745 & 2.673 \\
\hline & Jumlah & 22.168 & 17.911 & 26.563 \\
\hline
\end{tabular}

Sumber : data primer (2018)

Hubungan dengan pelanggan menjadi faktor sukses. Hal tersebut dikatakan juga oleh Hoffman dan Bateson (2006), bahwa semakin baik kualitas layanan suatu badan usaha, semakin tinggi pula kepuasan pelanggannya. Penentuan lokasi di dalam bisnis restoran merupakan faktor penting dalam kesuksesan. Walaupun memiliki konsep dan pelayanan yang baik namun dalam pemilihan lokasi yang tidak tepat maka usaha bisnis restoran tidak akan berhasil.

\section{Analisis Lingkungan Internal dan Eksternal}

Berdasarkan dari hasil analisis menggunakan metode CSF, maka dilakukan analisis faktor internal dan eksternalnya untuk kemudian dilakukan perumusan strategi menggunakan matriks SWOT. Analisis lingkungan Internal dan ekstrnal dengan tujuan untuk dapat dilakukan perumusan strategi menggunakan matriks SWOT. Hunger dan Wheelen (2004), mejelaskan bahwa matriks SWOT dapat diaplikasikan baik pada perusahaan bisnis tunggal maupun multi bisnis, dan bahkan untuk unit bisnis. Metode analisa SWOT merupakan metoda analisis yang berguna untuk melihat suatu topik atau permasalahan dari 4 sisi yang berbeda.

\section{Kekuatan Restoran GW}

a. Pelayanan konsumen yang ramah dan memuaskan, b. Memiliki SDM yang berkualitas,

c. Pemilik restoran selalu menjaga keharmonisan dengan karyawan/ pegawai,

d. Memilliki ciri khas makanan yang berasal dari Indonesia, India, dan Italia,

e. Design tempat yang menarik antara lain terdiri dari tiga design bangunan yaitu Jawa, Bali, dan Eropa,

f. Tempat strategis karena terletak dipinggir jalan.

\section{Kelemahan Restoran $G W$}

a. Harga relatif mahal, bila dibandngkan yang lain

b. Jam operasional restoran terbatas yakni pukul $18.00-22.00 \mathrm{WIB}$,

c. Tidak pernah mengadakan promosi dalam bentuk apapun,

d. Tidak menggunakan teknologi informasi modern (sosial media)

\section{Peluang Restoran GW}

a. Ada kebutuhan restoran privat atau cocok untuk acara keluarga, kantor, dan lain-lain,

b. Banyak wisatawan dari luar negeri yang tertarik untuk menyantap makan malam dalam suasana khusus,

c. Konsisten dalam menggunakan daging berkualtas dari Australia.

\section{Tantangan Restoran $G W$}

a. Persaingan yang ketat karena banyak restoran yang menyajikan menu yang sejenis,

b. Adanya persaingan harga yang kompetitif,

c. Harus mulai mengikuti tuntutan teknologi IT,

d. Selera konsumen yang mudah berubah atau bosan menyebabkan kerugian apabila tidak melakukan inovasi-inovasi baru

\section{Rumusan Strategi Bisnis}

Strategi bisnis restoran GW perlu upaya perbaikan sistem management internal agar usaha yang dilakukan memberikan keuntungan, mampu bersaing dengan pelaku yang ada, beradaptasi terhadap dinamika kebutuhan pasar sehingga usaha nya dapat berkelanjutan (David, 2011).

Ada 4 pendekatan dalam merumuskan strategi, yaitu 1) mengoptimalkan kekuatan untuk memanfaatkan peluang yang ada (S-O), 2) mengurangi kelemahan untuk memanfaatkan peluang yang ada (W-O), 3) menggunakan kekuatan untuk mencegah dan mengatasi ancaman dari luar (W-T), dan 4) mengurangi kelemahan untuk mencegah dan mengatasi ancaman dari luar (S-T). Pengembangan strategi bisnis restoran GW menggunakan SWOT sejalan dengan pendapat Ayub dan Razzaq (2013) yaang menjelaskan bahwa SWOT sangat efektif dalam penyusunan strategi pemasaran bisnis. Lebih lanjut, Ifediora (2014) bahwa SWOT sebagai alat untuk stabilitasi dan produktivitas organisasi usaha. 
Tabel 4. IFAS dan EFAS Restoran GW

\begin{tabular}{|c|c|c|c|c|}
\hline No & Kekuatan & Bobot & Rating & Bobot xRating \\
\hline 1 & Pelayanan konsumen yang ramah dan memuaskan & 0,10 & 3 & 0,30 \\
\hline 2 & Total quality management & 0,15 & 4 & 0,60 \\
\hline 3 & $\begin{array}{l}\text { Pemilik restoran selalu menjaga keharmonisan } \\
\text { dengan karyawan }\end{array}$ & 0,15 & 1 & 0,15 \\
\hline 4 & $\begin{array}{l}\text { Memilliki ciri khas makanan yang berasal dari } \\
\text { Indonesia, India, dan Italia }\end{array}$ & 0,20 & 4 & 0,80 \\
\hline 5 & $\begin{array}{l}\text { Design tempat yang menarik yaitu design bangunan } \\
\text { Jawa, Bali, dan Eropa }\end{array}$ & 0,20 & 4 & 0,80 \\
\hline \multirow[t]{3}{*}{6} & Tempat yang nyaman & 0,20 & 2 & 0,40 \\
\hline & Total Skor Tertimbang & 1,00 & & 3,05 \\
\hline & Kelemahan & Bobot & Rating & Bobot x Rating \\
\hline 1 & Harga yang cukup mahal & 0,35 & 3 & 1,05 \\
\hline 2 & $\begin{array}{l}\text { Jam operasional restoran Gadjah Wong dimulai pukul } \\
18.00-22.00 \mathrm{WIB}\end{array}$ & 0,20 & 1 & 0,20 \\
\hline 3 & $\begin{array}{l}\text { Tidak pernah mengadakan promosi dalam bentuk } \\
\text { apapun }\end{array}$ & 0,25 & 2 & 0,50 \\
\hline \multirow[t]{3}{*}{4} & $\begin{array}{l}\text { Tidak aktif menggunakan teknologi informasi modern } \\
\text { ( sosial media) }\end{array}$ & 0,20 & 2 & 0,40 \\
\hline & Total Skor Tertimbang & 1,00 & & 2,15 \\
\hline & Peluang & Bobot & Rating & Bobot xRating \\
\hline 1 & $\begin{array}{l}\text { Ada kebutuhan restoran privat atau cocok untuk } \\
\text { gathering keluarga, kantor, dan lain-lain }\end{array}$ & 0,25 & 2 & 0,50 \\
\hline 2 & $\begin{array}{l}\text { Banyak wisatawan dari luar negeri yang tertarik untuk } \\
\text { menyantap makan malam di restoran GW }\end{array}$ & 0,40 & 2 & 0,80 \\
\hline \multirow[t]{3}{*}{3} & $\begin{array}{l}\text { Konsistensi dalam menggunakan daging yang } \\
\text { berkualitas dari Australia. }\end{array}$ & 0,35 & 3 & 1,05 \\
\hline & Total Skor Tertimbang & 1,00 & & 2,35 \\
\hline & Ancaman & Bobot & Rating & Bobot x Rating \\
\hline 1 & $\begin{array}{l}\text { Persaingan yang ketat karena banyak restoran yang } \\
\text { sejenis }\end{array}$ & 0,30 & 2 & 0,60 \\
\hline 2 & Adanya persaingan harga yang kompetitif & 0,25 & 3 & 0,75 \\
\hline 3 & Harus mulai aktif mengikuti tuntutan teknologi IT & 0,15 & 2 & 0,30 \\
\hline \multirow[t]{2}{*}{4} & $\begin{array}{l}\text { Selera konsumen yang mudah berubah atau bosan } \\
\text { menyebabkan kerugian apabila tidak melakukan } \\
\text { inovasi-inovasi baru }\end{array}$ & 0,30 & 4 & 1,20 \\
\hline & Total Skor Tertimbang & 1,00 & & 2,85 \\
\hline
\end{tabular}

Berdasarkan Tabel 5 di atas dapat dikembangkan strategi bisnis untuk Restoran GW adalah sebagai berikut:

a. Strategi S-O adalah meningkatkan komunikasi dalam hal ketrampilan, ilmu pengetahuan budaya dan bahasa asing untuk pegawai; serta mengoptimalkan pengiklanan restoran pada baliho dan agen travel.

b. Strategi W-O adalah memberikan pengetahuan tentang pentingya gaya hidup sehat melalui menu daging yang berkualitas; serta menambahkan jam operasional restoran terutama mulai buka restoran. c. Strategi S-T adalah menonjolkan menu-menu unggulan yang tidak dimiliki restoran lain; serta meningkatkan inovasi-inovasi pada menu makanannya.

d. Strategi W-T adalah memperluas jaringan pasar dengan memanfaatkan teknologi informasi terkini untuk mempromosikan produk, membangun interaksi dengan konsumen sehingga dapat berkembang dan berkelanjutan. Itu semua sejalan dengan pendapat Steinhoff di dalam Solihin (2014), bahwa strategi bisnis meliputi seluruh aktivitas bisnis restoran yakni menyediakan barang dan jasa yang diperlukan atau diinginkan oleh konsumen. 


\section{KESIMPULAN DAN SARAN}

Faktor penentu keberhasilan restoran GW yaitu Faktor Konsep, Hubungan dengan Pegawai, Ketertarikan Budaya, Kondsi Lingkungan yang Kompetitif, Hubungan dengan Pelanggan, dan Pemilihan tempat atau lokasi.

Strategi bisnis Restoran GW secara komprehensif meliputi ke 4 pendekatan strategi dari hasil identifikasi kekuatan, kelemahan, peluang dan ancaman. Secara spesifik strategi itu adalah meningkatkan kualitas karyawan, meningkatkan kualitas produk dan inovasinya, mengunggulkan menu spesifik, menambah waktu pelayanan, serta melakukan promosi iklan dan memperluas jaringan dengan media sosial.

\section{DAFTAR PUSTAKA}

Anonim, 2020. Aplikasi Dataku DIY. Bappeda DIY Ayub A dan Adeel R. 2013. A Conceptual framework on evaluating SWOT analysis as the mediator in strategic marketing planning through marketing intelligence. European Journal Business and Social Sciences. 1: 91-98.

David FR. 2011. Strategic Manajemen Strategis Konsep, Edisi 12, Penerbit Salemba Empat, Jakarta.

Devito J. 2009. Komunikasi Antar Manusia. Pamulang - Tangerang Selatan: Karisma

Gikonyo L. 2015. Critical success factors for franchised restaurants entering the Kenyan Market: Franchishors Perspective. 1-8.

Gurhananda I dan Harimukti W. 2014. Strategic marketing for restaurant business (Case study of Lawangwani Café). Journal Business and Management. 3 (1) : 112-131.

Hoffman K, Douglas, John EG, Bateson. 2006. Service Marketing. Concepts, Strategies, \& Cases, Third Edition. Penerbit: Thomson South Western, USA.

Hunger JD dan Wheelen TL. 2004. Strategic Management and Business Policy $\left(10^{\text {th }}\right.$ edition). Texas: Addison Wesley Publissing Company Inc.

Ifediora O. 2014. Organization's stability and productivity: the role of SWOT analysis an acronym for strength, weakness, opportunities, and threat. International Journal Innovative and Applied Research. 2 (9): 23-32.
Indrayana FB. 2006. Desain Interior Restoran Arma di Ubud Bali Denpasar, Institut Seni Indonesia. Jakarta: PT Elex Media Computindo.

Kotler P. 2005. Manajemen Pemasaran. Edisi millennium, Jilid 3, Jakarta : Penerbit Indeks.

Marsum W. 2005. Restoran dan Segala Permasalahannya. Edisi 4. Yogyakarta: Andi

Muslim Bin Aqeel A. 2011. Determinants of business success. International Journal Human Resource Studies. 1 (1): 99-110.

Purwadi D. 2018, Perumusan strategi pemerintah daerah dalam pengembangan umbi umbian lokal di Yogyakarta. Jurnal Teknologi \& Industri Hasil Pertanian. 23(2): 75

Putri NE, Astuti R, dan Putri SA. 2014. Perencanaan strategi pengembangan restoran menggunakan analisis SWOT dan metode QSPM: Studi Kasus Restoran Big Burger Malang. Industria: Jurnal Teknologi dan Manajemen Agroindustri 3 (2). 99-106.

Rahman, Fadlur J, dan Rahmah DM. 2018. Identifikasi proses dan strategi bisnis pada Kadatuan Koffie menggunakan analisis SWOT. Industria: Jurnal Teknologi dan Manajemen Agroindustri.7 (3): 161-169.

Sarjono B. 2013. Pengelolaan strategi dalam persaingan bisnis. Jurnal Manajemen Strategi. 9: $58-61$.

Setyorini H, Effendi M, dan Santoso I 2016. Analisis strategi pemasaran menggunakan matriks SWOT dan QSPM (Studi Kasus: Restoran WS Soekarno Hatta Malang), Teknologi dan Manajemen Agroindustri. 5 (1): 46-53.

Škare M dan Stjepanović S. 2015. Measuring business cycles: A review. Contemporary Economics. 10 (1): 83-94.

Smart PA, Maddern H dan Maull RS. 2009. Understanding business process management: implications for theory and practice. British Journal Management. 20: 491-507.

Solihin I. 2014. Pengantar Bisnis. Jakarta: Penerbit Erlangga.

Ward J dan Peppard J. 2002. Strategic Planning, for Information Systems. New York: Jhon Wiley \& Sons, Inc. 